\title{
PAUL RICOEUR Y LA HISTORIA. ENTREVISTA A FRANÇOIS DOSSE ${ }^{1}$
}

\author{
Paul Ricoeur and the History. An Interview to François Dosse
}

\section{Mariana Leconte}

\begin{abstract}
La entrevista que aquí presentamos tuvo lugar en mayo de 2010, en Buenos Aires, con ocasión de la visita de François Dosse a esa ciudad para la presentación de la traducción castellana de su biografía cruzada de Gilles Deleuze y Félix Guattari ${ }^{2}$ en la Feria Internacional del Libro ${ }^{3}$. Agradezco profundamente a la Dra. Marie-France Begué, la generosa intermediación que volvió posible este diálogo.
\end{abstract}

$<$ François Dosse $><$ History $><$ Paul Ricoeur $>$

M.L.: Sintiéndome, en cierto modo, mediadora entre Ud. y los historiadores de mi región y articulando un diálogo entre la reflexión filosófica y la práctica historiográfica, quisiera que formulara, brevemente, cuál es, a su criterio, el valor de Paul Ricoeur para los historiadores.

F.D.: Ricoeur es totalmente fundamental. Porque, en efecto, respecto de la Historia, estamos en este momento en Francia en una situación de cuestionamiento de la certeza. De la certeza de la Escuela histórica francesa - la Escuela de los Annales-, en su primera, segunda y tercera generación, que ha reflexionado sobre el método y el oficio del historiador, pero que ha desconocido a la Filosofía. En Francia, la Historia ha tenido una doble desconfianza hacia la Filosofía. Por una parte, por el rechazo a la Filosofía de la historia -con la visión, de Hegel, de que la razón forma

\footnotetext{
${ }^{1}$ François Dosse es un historiador francés, especialista en historia intelectual, autor, entre otros numerosos libros y artículos, de: Histoire en miettes, Des 'Annales'á la Nouvelle Histoire, París, 1987; Paul Ricoeur: les sens d'une vie, Paris, 1997; Michel de Certeau: Le marcheur blessée, París, 2002; Paul Ricoeur et las sciences humaines, París, 2007.

${ }^{2}$ François Dosse, Gilles Deleuze-Félix Guattari, Biografía cruzada, Buenos Aires, Fondo de Cultura Económica, 2009, 692 pp.

${ }^{3}$ En el marco de esa visita, dictó además, en la Universidad Nacional de San Martín, la Conferencia: "La guerra de las memorias".
} 
parte de un proceso histórico y teleológico-. Frente a esto, los historiadores privilegiaron la empiria, la experimentación, la realidad factual...

Por otra parte, se da en Francia otra situación que es el hecho de que los historiadores franceses son formados junto con otra disciplina, que es la Geografía. Geografía e Historia se mezclan en la formación. Se forman profesores de "Historia y Geografía" para los Colegios, Liceos y también Universidades y estos profesores están marcados por su formación de historiadores y de geógrafos, y alejados de la Filosofía. No ocurre lo mismo en otros países, Alemania, por ejemplo, donde los historiadores están próximos a los filósofos, los antropólogos, etc. Es un problema nacional, este matrimonio de la Geografía y la Historia. Tiene que ver con la cuestión de la identidad francesa: del estado-nación, la Nación, Francia. Con una crisis de identidad nacional que tiene una razón histórica: la guerra de 1870, con la confiscación de Alsacia y Lorena por Alemania...Esta identidad nacional se funda sobre la historia, el territorio, las fronteras.

Entonces, la Filosofía estuvo a la distancia. A partir del momento en que la Historia, a través de los Annales, se unifica más bien con las ciencias sociales: Economía, Demografía, Sociología, Antropología, etc., el paradigma de los Annales se vuelve, con Braudel y otros, el jefe de orquesta de las ciencias sociales, con el ideal de certeza... con esa reorientación de la investigación. No sintieron la necesidad de acercarse a la Filosofía.

Desde mi punto de vista, no se siente la necesidad hasta el momento en que, apoyándose sobre ciertos paradigmas -el Durkheimismo, el Estructuralismo, todo el diálogo entre Braudel y Levi-Strauss- hubo como un estallido de la Historia, con Foucault, con la reorinteración que le dió Pierre Nora en su obra publicada por Gallimard ${ }^{4}$...Hubo un estallido que desbordó las fronteras de un paradigma que lo englobaba todo en Francia, muy rico, muy fecundo y que se había vuelto un producto de exportación -que llegó a Brasil, a Chile, incluso a la Argentina.

En fin, en ese triunfo, el paradigma de los Annales no sintió nunca la necesidad de alimentarse de la Filosofía, tampoco de las obras de Ricoeur.

Acercándonos a Ricoeur, hay que tener en cuenta, por otra parte, que él empieza a tratar el problema de la Historia en su texto "Historia y verdad"5 de 1955, que es un texto fundamental y que en su momento no fue para nada recibido por los historiadores. Otro factor por el cual Ricoeur no ha sido escuchado por los historiadores fue que, debido a su recorrido personal, estuvo bastante descentrado del movimiento de la intelectualidad francesa. Ese descentramiento se marca ya desde el año 1965, cuando se

${ }^{4}$ Pierre Nora, Les lieux de mémoire, Paris, Gallimard, 3 tomos : tomo I (1984), tomo II (1987), tomo III (1992).

${ }^{5}$ Paul Ricoeur, Histoire et verité, París, Éditions du Seuil, 1955, 1964 (2ºd.). Traducción castellana: P. Ricoeur, Historia y verdad, tr. Madrid, Encuentro, 1990. 
publica la Interpretación de Freud ${ }^{6}$, cuando recibe golpes muy duros de parte de Lacan y de los discípulos de Althusser y Lacan. Eso lo afecta de gran manera. Su reacción fue volver a fuentes antiguas. Por otra parte, Ricoeur fue utilizado para impulsar el ingreso de Foucault al Collège de France y él se sintió muy instrumentalizado con esta situación. La pugna por el ingreso fue una pelea muy dura, una guerra perdida de antemano. Su vida privada afectó su posición intelectual y, para coronar esto, sucede el famoso episodio de Nanterre ${ }^{7}$. Ricoeur entonces se va de la escena francesa: a Louvain y, luego, a Chicago ${ }^{8}$.

Es necesario esperar a los años ' 80 para que haya una especie de recepción en la disciplina de la Historia, de lo que él decía. Una recepción entre los intelectuales franceses. Ricoeur vuelve a Francia en el ' 83 y entre los años ' 85 y ' 88 comienza a ser el centro, el objeto de discusión por parte de los historiadores. El coloquio organizado por Esprit ${ }^{9}$ es un ejemplo de ello. Roger Chartier comenzará a discutir los textos de Ricoeur.

Los años ochenta son, entonces, los años de retorno de Ricoeur a la escena intelectual francesa, y los historiadores comienzan a interrogarse sobre la orientación que tenían. El año 1984 es el año de cristalización de la crisis del paradigma de los Annales. Yo, personalmente, he contribuido a ella también. Escribí un libro en 1987: La historia en migajas ${ }^{10}$, que fue traducido y publicado en castellano por la Universidad Iberoamericana de México -un libro que tuvo mucha resonancia- y que refleja ese momento de crisis del paradigma de los Annales. Luego, efectivamente, un año después, en Abril de 1988, los Annales publicaron un número de la revista, dedicado a esta circunstancia, titulado "Historia y ciencias sociales: ¿un giro crítico?"l1. La editorial de ese número de los Annales dice: "Estamos en este momento preguntándonos en qué modelo estamos.... estructuralismo, durkheimismo...No nos hemos cuestionado suficientente sobre la noción de interpretación, sobre la noción de agente o actores, etc". Una ruptura radical con los Annales. En esta editorial se plasma una frase muy significativa: "La sociedad no es una cosa", mientras que Durkheim había dicho "La sociedad es una cosa", contribuyendo a formar

\footnotetext{
${ }^{6}$ Paul Ricoeur, De l'interpretation. Essai sur Freud, Paris, Éditions du Seuil, 1965. Traducción castellana: P.R, Freud, una interpretación de la cultura, Buenos Aires/ México, Siglo XXI, 1970.

${ }^{7}$ Se refiere Dosse al fracaso que representó para Ricoeur su imposibilidad de resolver, como Decano de la Facultad de Letras de la Universidad de Nanterre, el estallido estudiantil de 1968. Para mayor información sobre la vida y el recorrido intelectual de Ricoeur, cfr. Paul Ricoeur, Autobiografía intelectual, Buenos Aires, Nueva Visión, 1997. [Nota de la Editora]

${ }^{8}$ En ambos lugares, dictó cursos como profesor invitado.

${ }^{9}$ Cfr. Esprit, juillet-août 1988, n ${ }^{\circ}$ s 7/8, número dedicado a Ricoeur.

${ }^{10}$ François Dosse, L'histoire en miettes, Des Annales à la «nouvelle histoire», Paris, La Découverte, 1987.

${ }^{11}$ «Histoire et sciences sociales. Un tournant critique ?», Les Annales, Annales, Histoire, Sciences Sociales, $43^{\mathrm{e}}$ année, $\mathrm{n}^{\circ} 2$, (mar.-apr. 1988).
} 
esa visión ahora en crisis. Hay una puesta en cuestión de la idea de nueva alianza, un interrogarse sobre el giro, los actores, la temporalidad, no sólo privilegiando la larga duración sino también la corta. En esos momentos, yo, personalmente, tuve el estatuto de "persona horrible", por ser la persona que les impedía "pensar en redondo".

Luego, en noviembre/diciembre de 1989, aparece otro número muy importante de Annales $^{12}$. Todo el número temático de Annales fue dedicado a la discusión de "Historia y ciencias sociales: ¿un giro crítico?" y a artículos relacionados y al período precedente. Pienso en el artículo de Roger Chartier "Le monde comme réprésentation", pienso en el artículo de Alain Boureau "Propositions pour une histoire restreinte des mentalités", pienso en el artículo de Giovanni Levi sobre "Les usages de la biographie".

Es un momento de giro. Roger Chartier describió este momento como un momento de incertidumbre, de cuestionamiento. Fue el momento en que los historiadores empezaron a mirar la Filosofía de la historia, y a Ricoeur, comenzaron a interrogarse sobre la fundamentación filosófica de las nociones que usaban sin cuestionar o sin tener conciencia de lo que decían: como el tiempo, la verdad, la narración, etc. Con el tiempo, sintieron el deseo de interrogarse y, es entonces, cuando Ricoeur llega con la obra monumental que es Tiempo y narración ${ }^{13}$-donde Ricoeur dialoga, como siempre lo hizo, con las ciencias sociales en general, pero con la Historia en particular- todos los historiadores comienzan a interrogarse sobre ese texto y a apropiarse de él. Además estuvo Bernard Lepetit, un joven historiador fallecido repentinamente, que fue el principal escritor y diseñador de un texto sobre el giro crítico; fue el primer historiador con esa visión crítica y en iniciar el diálogo. Bernard Lepetit era en esa época el secretario de redacción de la revista de Annales. Escribió en esos años trabajos en relación con estos temas, en los que busca salir del atolladero a través de la hermenéutica y moviliza para ello manifiestamente el texto de Ricoeur. A tal punto que, cuando Ricoeur lee a Lepetit, queda impresionado. Hay algo que se anuda allí y que será compartido por Lepetit, Chartier, etc., que es la cuestión de la narratividad y, entonces, se apropiaron de la orientación, sobre todo del Tomo I, de Tiempo y Narración. A fines del año '90, los historiadores están empantanados en el giro crítico y Ricoeur da una salida.

\footnotetext{
${ }^{12}$ « Histoire et Sciences Sociales. Un tournant critique », Annales, Économies, Societés, Civilisations, $44^{\circ}$ Année, $n^{\circ} 6$ (nov-déc. 1989).

${ }^{13}$ Paul Ricoeur, Temps et récit I: l'historicité et le récit, Paris, Éditions du Seuil, 1983; P.R., Temps et récit II: la configuration du temps dans le récit de fiction,Paris, Éditions du Seuil, 1985; P.R, Temps et récit III: le temps raconté, Paris, Éditions du Seuil, 1985. La traducción castellana de estas obras vio la luz en la Editorial Siglo XXI, entre los años 1995 y 1996.
} 
M.L.: ¿Cuáles serían las nociones que Ricoeur ofrece a los historiadores? ¿Cuál es el aporte principal de su pensamiento?

F.D.: Para terminar con todo este arco, lo que moviliza en verdad totalmente a los historiadores es la reflexión de La memoria, la historia, el olvido ${ }^{14}$. En ese momento de centralidad de la discusión de la memoria y de la relación de la memoria y la historia, el trabajo de clarificación de los conceptos de Paul Ricoeur es esencial. Dado que Ricoeur hasta entonces no había sido seriamente tenido en cuenta en Francia, es muy significativo, por ejemplo, recordar que La memoria, la historia, el olvido dio lugar a un gran dossier en la revista Le Debat ${ }^{15}$. Por otra parte, justo antes de la publicación del libro -en junio de 2000- Ricoeur es invitado a dar la conferencia organizada por la Escuela de Altos Estudios (de la Escuela de los Annales), presidida entonces por Jacques Revel. Es una tradición en Francia que una gran personalidad sea la invitada a dar esta conferencia, conocida con el nombre de Conferencia Marc Bloch. Paul Ricoeur fue invitado a dar esa conferencia ante 900 personas. El texto de la conferencia fue luego publicado en la revista de los Annales $^{16}$. De la misma manera que en la Escuela de los Annales hubo una época en que se apropiaron de los textos durkheimianos, etc, el punto de balanceo lo constituyó entonces este texto de Ricoeur.

M.L.: Cuando se lee La memoria, la historia, el olvido desde la Filosofía, el lector se topa con dificultades para entender cuál es la articulación propia de Ricoeur, en medio de las diferentes concepciones que articula o con las que dialoga. ¿Dónde está el aporte específico de Ricoeur? ¿O el valor está precisamente en el diálogo mismo?

F.D.: Lo que podemos comprobar es el hecho de que Ricoeur siempre ha respondido a esta cuestión desde su concepción hermenéutica, unida a la filosofía de la acción, la pragmática - que es el aporte norteamericano. La posición de Ricoeur es una posición a la vez de hermeneuta y de filósofo pragmático y la disciplina histórica en Francia hoy está en un doble giro, a la vez pragmático y hermenéutico. A los dos ha aportado Ricoeur. El encuentro mayor está entre el decir y el hacer, lo que significa obrar, lo que significa interpretar ¿Qué significa obrar? ¿Y en qué consiste la interpretación textual?

M.L.: Michel de Certeau está muy cerca de Ricoeur...

F.D.: Sí, yo lo he mostrado ${ }^{17} \ldots$

\footnotetext{
${ }^{14}$ Paul Ricoeur, La mémoire, la histoire et l'oubli, Paris, Éditions Du Seuil, 2000. Traducción castellana: P. R., La memoria, la historia, el olvido, Buenos Aires, Fondo de Cultura Económica, 2004.

${ }^{15}$ Revue Lé Debat, Histoire, Politique, Societé, $\mathrm{n}^{\circ}$ 122, nov-déc. 2002. La revista, editada por Gallimard, es dirigida por Pierre Nora.

${ }^{16}$ Paul Ricoeur, "L'écriture de l'histoire et la représentation du passé ", en : Annales. Histoire, Sciences Sociales, juillet-août 2000, $\mathrm{n}^{\circ}$ 4, pp.731-747.

${ }^{17}$ F. Dosse, Paul Ricoeur-Michel De Certeau. La histoire, entre le dire et le faire, Paris, Éditions de
} 
M.L.: ¿Cuál es el plus que aporta Ricoeur al trabajo ya hecho por De Certeau?

F.D.: No hay que olvidar que De Certeau no es filósofo. Ricoeur aporta la historia del pensamiento desde Aristóteles, (Ricoeur decía que cuando pensaba tenía todos los libros de la historia de la filosofía en su mesa, en la imaginación). Un aporte fundamental. De Certeau, por otra parte, muere en 1986. Ricoeur lo sobrevive y puede participar de otros debates; puede plantear la centralidad de la cuestión de la memoria, en relación con la historia, cuestión tematizada por él después de esa fecha.

M.L.: ¿No ve un aporte de Ricoeur en toda esa remisión a lo ontológico, de la comprensión, de la temporalidad, etc?

F.D.: Atención. Es muy importante pensar que, para Ricoeur, la cuestión de la ontología nunca es el bajo fondo o un cimiento, sino que también se mueve. Es significativo cómo lo muestra la estructura misma de $L a$ memoria, la historia, el olvido: I. Fenomenología de la memoria, II. Epistemología de la historia, III. Ontología de la condición histórica. La ontología de la condición histórica es un horizonte y el horizonte del horizonte es el perdón, lo supraético, una extraterritorialidad dentro de su libro.

M.L.: Podría decirse que Ricoeur no entiende la ontología como fundamento porque recibe la herencia heideggeriana y la comprensión de lo ontológico como lo 'originario'.

F.D.: Ricoeur se resistió a la ontología heideggeriana... (sobre todo, a la del segundo Heidegger).

M.L.: Pero no puede dejar de reconocerse la influencia heideggeriana, al menos, en su modo de entender la comprensión, no solamente como un recurso epistemológico, sino como un modo de ser.

F.D.: Sí...Pero esas cuestiones no son tan interesantes para el historiador. (Volviendo a la relación Ricoeur-De Certeau) La proximidad De CerteauRicoeur no fue siempre evidente. Ricoeur no había leído mucho a De Certeau. Yo había escrito una biografía de Ricoeur y cuando escribía la biografía de De Certeau, lo empujé en cierto modo a Ricoeur a que lo conociera, lo leyera. Él era reticente, al principio, porque lo juzgaba como sociólogo, de corte marxista, cercano a Lacan - porque De Certeau había estado próximo de la Escuela freudiana de París-. Veía su posición como un exceso de sociologismo. El encuentro de Ricoeur con De Certeau fue un encuentro póstumo. Tengo testimonios directos de Paul Ricoeur de la fascinación extática que le produjo descubrir la obra de De Certeau y eso es directamente visible en La memoria, la historia, el olvido.

L'Herne, 2006. Traducción castellana: Paul Ricoeur-Michel De Certeau, La historia entre el decir y el hacer, Buenos Aires, Nueva Visión, 2009. 
M.L.: De las dos últimas preguntas que quería formularle, dado que nos quedan sólo 10 minutos de tiempo, elija Ud. cuál responder: 1) En el debate actual de la historiografia, ¿cuáles son, a su criterio, las cosas dignas de pensar para un filósofo? 2) ¿Qué sucede cuándo en una sociedad dada hay una pluralidad excesiva de narraciones o cuando las narraciones históricas han estallado, como en nuestra situación argentina?

F.D.: Respecto de la última pregunta, la remito a un artículo de mi autoría en la revista Cités del $2008^{18}$ sobre la historia y la guerra de las memorias, que no he traído y que está centrado en Ricoeur. Respecto de la primera, tengo aquí otro artículo sobre la cuestión de la importancia de la obra de P. Ricoeur para los historiadores, aparecido en el Bulletin de la Société de l'Histoire du Protestantisme Français ${ }^{19}$. Va a reencontrar varias cosas que dije aquí -aunque escritas y no habladas-. Presento allí las cosas que me parecen importantes para los historiadores: la cuestión del acontecimiento, vuelve. No el acontecimiento como lo abordó el siglo XIX, sino el acontecimiento después, justamente, del giro hermenéutico. Pues ahí, los historiadores tienen la oportunidad de abordar las huellas del acontecimiento. No solamente la cosa, no solamente la factualidad, no solamente las causas del acontecimiento sino sobre todo las huellas del acontecimiento. La cuestión de la articulación memoria-historia. La cuestión de la biografía. Ricoeur aporta una noción de biografía nueva. He dado recientemente una conferencia sobre este punto: "La biografía a la prueba de la identidad narrativa" 20 , contra la ilusión biográfica. La cuestión de la distinción entre memoria e historia. La cuestión de la problemática de los "lugares de memoria" (noción acuñada por Pierre Nora). De qué manera se pueden aproximar la noción de P. Nora de "lugares de memoria" y la comprensión ricoeuriana de la relación entre memoria e historia. Ricoeur pasó al lado de P. Nora, no lo comprendió del todo, no leyó los buenos textos de P. Nora -aunque yo le había dicho que los leyera-. Lo reconoció en la revista Le Débat, reconoció que allí hubo un diálogo de $\operatorname{sordos}^{21}$. Entre lo que dice Nora del libro de Ricoeur -(Nora también pasa al lado del libro de Ricoeur)- y lo que dice Ricoeur de Nora...

De alli en más, la entrevista abandonó su referencia temática y fue cobrando el matiz de una amena conversación de despedida, con la entrega de textos, sugerencias de lecturas y la disponibilidad para futuros diálogos por vía electrónica, signos de una generosidad y calidez personales, que marcaron el ritmo de un encuentro memorable.

\footnotetext{
${ }^{18}$ François Dosse, "L'histoire à l'épreuve de la guerre des mémoires ", en Cités, "Paul Ricoeur, Interpretation et reconnaissance $», 2008 / 1, \mathrm{n}^{\circ} 33$.

${ }^{19}$ François Dosse, "L'importance de l'oeuvre de Paul Ricoeur pour la pratique historienne", en Bulletin de la Société de l'Histoire du Protestantisme Français, Tome 152, 2006, pp. 647-665.

${ }^{20}$ François Dosse, "La biographie à la preuve de l'identité narrative. Contre l'illusion biographique", en el Colloque International "L’Héritage littéraire de Paul Ricoeur", París, Junio de 2010.

${ }^{21}$ Paul Ricoeur, "Mémoire: approches historiennes, approche philosophique", en Lé Debat, Histoire, Politique, Societé, nº 122, nov-déc. 2002, pp. 41- 62.
} 